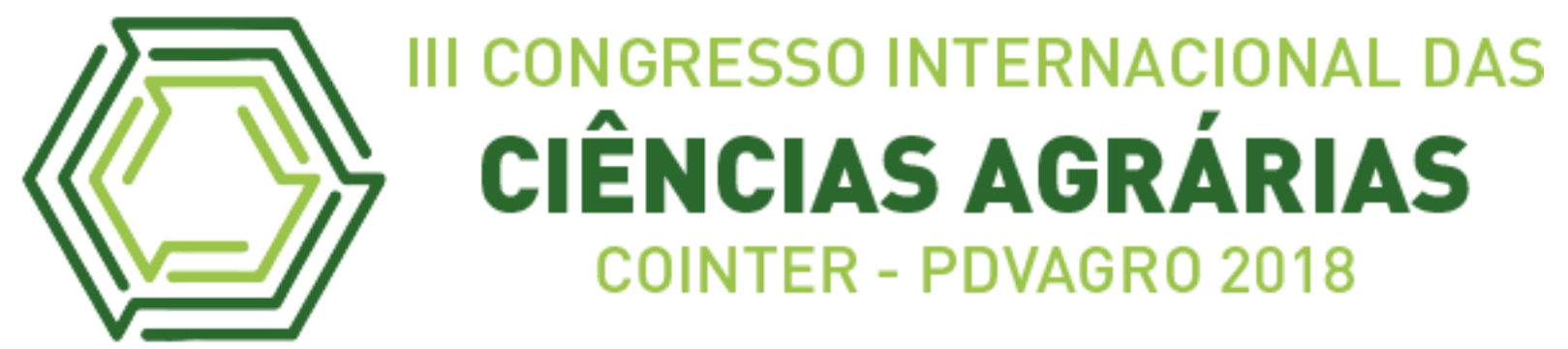

\title{
DIVERSIDADE DE FUNGOS MICORRÍZICOS ARBUSCULARES EM SOLO DE CERRADO SOB PASTAGEM
}

\section{DIVERSITY OF ARBUSCULAR MYCORRHIZAL FUNGI IN CERRADO SOIL UNDER PASTURE}

Apresentação: Pôster

Mickaelle Alves de Sousa Lima ${ }^{1}$; Ana Paula Brito de Sousa ${ }^{2}$; Wanderson Lima Cunha ${ }^{3}$; Ivaneide de Oliveira Nascimento ${ }^{4}$; Gerbeli de Mattos Salgado ${ }^{5}$

DOI: https://doi.org/10.31692/2526-7701.IIICOINTERPDVAGRO.2018.00434

\section{Introdução}

O Cerrado brasileiro destaca-se na produção de grãos, fibras e energia devido aos seus solos possuírem boa aptidão agrícola, sendo maior parte constituído por LATOSSOLOS, que representam 50 a $60 \%$ dos solos desse bioma (SOUZA et al., 2004). O interesse em estudo no Cerrado sobre a diversidade e atividade de microorganismo do solo está cada vez maior, principalmente com os que cumprem função de ciclagem de nutrientes como, por exemplo, os fungos micorrízicos (BERBARA; SOUZA; FONSECA, 2006).

Entre os microrganismos que habitam o solo há grupos de essencial importância, como os fungos micorrízicos arbusculares (FMA) (MOREIRA; SIQUEIRA, 2006). As micorrizas arbusculares, entres os tipos de micorrízas existentes, são consideradas com maior número de hospedeiro, abrangendo muitas espécies de valor econômico e ecológico (NOVAIS, 2008). O trabalho teve como objetivo registrar ocorrência de fungos micorrízicos arbuculares em solos de Cerrado sob pastagem no Estado do Maranhão.

\section{Fundamentação Teórica}

\section{Fungos Micorrízicos arbusculares}

Os Fungos Micorrízicos Arbusculares (FMA), geralmente, ocorrem de forma natural no solo e são componentes naturais dos sistemas de produção agrícola. Grande parte das

\footnotetext{
${ }^{1}$ Engenharia Agronômica, UEMASUL, mickaellesousalima@gmail.com

${ }^{2}$ Engenharia Florestal, UEMASUL, paulabrito1619@gmail.com

${ }^{3}$ Ciências Biológicas, UEMASUL, lwanderson8c@gmail.com

${ }^{4}$ Doutora, UEMASUL, ivaneide_agro@yahoo.com.br

5 Doutora, UEMASUL, gerbeli_salgado@hotmail.com
} 
plantas tem suas raízes colonizadas pelos FMA, que contribuem para o seu crescimento, principalmente em solos com baixa fertilidade natural (FERNANDES, 2011).

\section{Taxonomia dos Fungos Micorrízicos Arbusculares}

A identificação dos fungos micorrízicos envolvendo simbiose é uma condição necessária para distinguir as associações preferenciais entre as espécies de fungos e as plantas, comparando resultados de pesquisas em diversas condições ambientais e recomendar práticas de manejo adequadas (SILVA JÚNIOR, 2016).

\section{Metodologia}

- O estudo foi realizado em áreas de pasto em dois municípios maranhenses: Governador Edson Lobão e Ribamar Fiquene, áreas que correspondem ao Cerrado maranhense. Em cada município foram selecionadas duas áreas com pasto formado por capim Brachiária decumbens, em cada área foram coletadas cinco amostras de solo compostas por cinco subamostras, coletas a 0-20 cm de profundidade e com uma distância de $3 \mathrm{~m}$ entre si.

Após a coleta, as amostras foram armazenadas em sacos plásticos, identificadas, acondicionadas em caixa térmica e levadas ao laboratório. Em laboratório, o solo foi seco ao ar e em seguida acondicionado em freezer a $4^{\circ} \mathrm{C}$ até análises de densidade e identificação dos FMA. Os esporos foram extraídos de $50 \mathrm{~g}$ de solo, pesados em um béquer de 1L, onde se acrescentou água e em seguida a amostra foi agitada e deixada descansar por 20 minutos. Após decantar, o líquido foi vertido em um conjunto de peneiras de 710 e $53 \mu \mathrm{m}$ (GEDEMANN e NICOLSON, 1963).

Após a "lavagem" do solo, o sobrenadante retido na peneira de $53 \mu \mathrm{m}$ foi colocado em tubos falcon levados para centrifugação a uma velocidade de $3000 \mathrm{rpm}$ por cinco minutos, para separação das partículas do solo. Após a centrifugação, o sobrenadante foi descartado e ao corpo de fundo acrescentado uma solução de sacarose 45\% (JENKINS, 1964), em seguida os tubos foram levados para centrífuga, por três minutos a uma rotação de $3000 \mathrm{rpm}$.

Finalizada a centrifugação o material foi vertido na peneira de $53 \mu \mathrm{m}$ e lavado com água destilada para a retirada da sacarose, em seguida colocado em placas de Petri para contagem dos esporos com auxílio de lupa estereoscópica (40 x). Durante a contagem dos esporos os mesmos foram separados por semelhança quanto ao tamanho, cor e forma, sendo posteriormente colocados em lâminas de vidro com PVLG (Álcool Polivinil em Lacto- 
Glicerol) e em lâminas com PVLG + Melzer (1:1) para serem observados em microscópio óptico, para identificação.

Os dados obtidos foram comparados com a descrição das espécies em Schenck e Pérez (1988) e na página da International Culture Collection of Vesicular Arbuscular Mycorrhizal Fungi (Invam 2001).

Os gêneros dos FMA foram identificados com base na forma, tipo e número de paredes, presença ou ausência de cicatrizes e hifas de sustentação, presença e forma do bulbo suspensor, número de hifas no glomerosporo, estruturas de germinação (placas germinativas e orbs) e reação ao Melzer. Os gêneros foram ordenadas em quatro categorias, baseadas em sua frequência de ocorrência (IF) segundo Zhang et. al, (2004): espécie dominante (IF > 75\%), espécie mais comum $(50>\mathrm{IF}<75 \%)$, espécie comum $(25>\mathrm{IF}<50 \%)$, e espécies raras (IF $\leq$ $10 \%)$.

\section{Resultados e Discussões}

Os gêneros de FMA encontrados foram: Acaulospora sp1.; Claroideoglomus sp1.; Gigaspora sp1.; Glomus sp1.; Glomesporos sp1.; Scutellospora sp1.; Paraglomus sp1., sendo que os encontrados em maior quantidade foram Glomus sp1 (2197); Acaulospora sp1 (836) e Scutellospora sp1 (706) (Figura 1).

Os gêneros Acaulospora sp., Glomus sp., Scutellospora sp., foram observados nas duas áreas coletadas, porém em quantidades diferentes. Em Governador Edson Lobão foram encontrados 1190 esporos do gênero Glomus sp1, 560 esporos do gênero Acaulospora sp. e 140 esporos do gênero Scutellospora sp1. Já em Ribamar Fiquene foram encontrados 1007 esporos do gênero Glomus sp1 para o gênero Scutellospora sp1 encontrou-se 566 esporos e 276 do gênero Acaulospora sp 1.

Estes resultados foram semelhantes aos encontrados por Miranda (2008) em estudo com diferentes solos do Cerrado nativo e cultivado, onde o mesmo observou predominância dos gêneros Glomus sp., e Acaullospora sp. Essa ocorrência pode ser explicada devido á maior adaptação destes gêneros a solos submetidos a diferentes manejos e usos. (SILVA JÚNIOR et al., 2006).

Os gêneros encontrados em menor quantidade, foram Claroideoglomus sp. (10 esporos), Gigaspora sp., (4 esporos), Glomesporos sp., (25 esporos) e Paraglomus sp., (23 esporos), (Figura 1), sendo que em Governador Edson Lobão os gêneros Glomesporos sp. e 
Paraglomus sp. não foram observados já em Ribamar Fiquene os gêneros não observados foram: Claroideoglomus sp. e Gigaspora sp.

Figura 1. Quantidade de esporos em área de pasto em dois municípios maranhenses sob solo de Cerrado. Fonte:

Própria

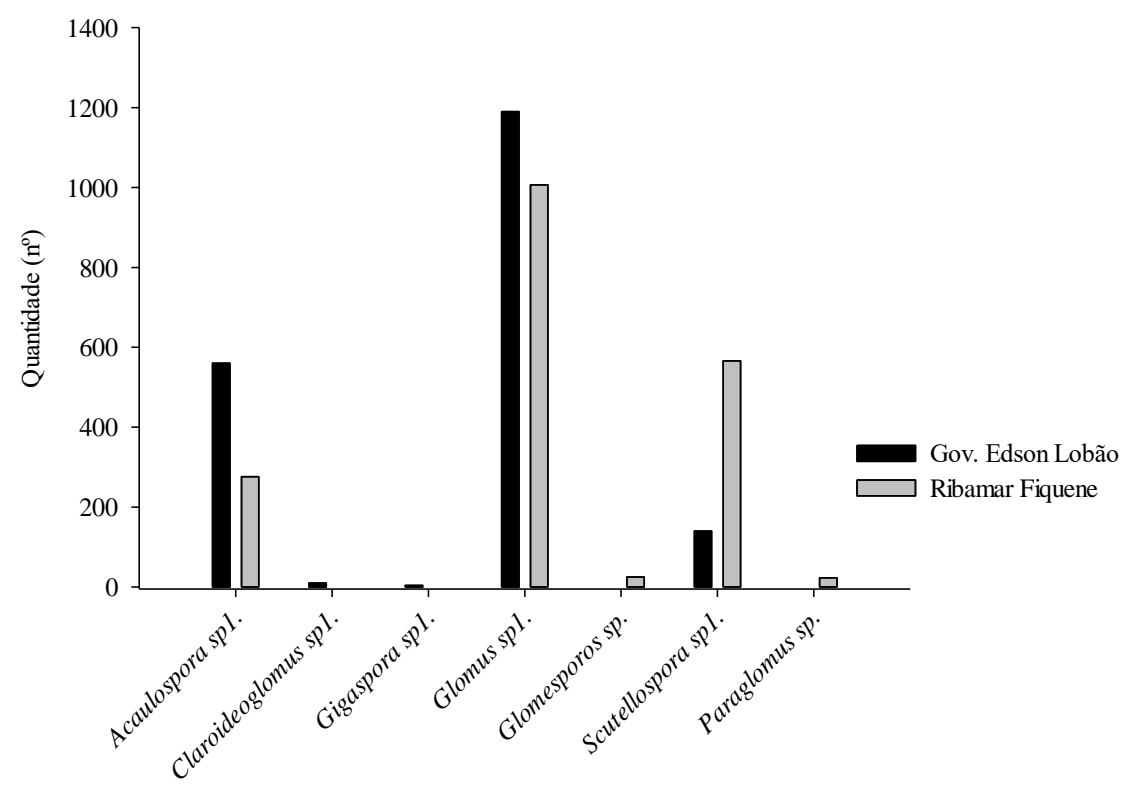

As espécies pertencentes à família Glomeraceae encontradas no presente trabalho e em outros estudos, foram consideradas em sua maioria generalistas, isto pode ser explicado por causa de sua grande capacidade de esporulação e da alta adaptabilidade a solos agrícolas (FERREIRA et al., 2012).

Quanto à distribuição total de espécie de FMA entre as áreas estudadas, observou-se predomínio do gênero Glomus sp., nas duas áreas coletas, com IF mais comum, sendo que em Governador Edson Lobão o IF foi igual a 62,50\% e em Ribamar Fiquene de 53,08\%, resultados estes semelhante ao de Silva (2010) no qual relata que gênero Glomus sp. e Acaulospora sp., apresentaram-se com maior porcentagem comparando-se com demais gêneros encontrados em seu estudo.

Entre a diversidade de gêneros identificados, apenas 2 gêneros apresentaram com IF de espécie comum sendo estes: Acaulospora sp., com 29,41\% em Governador Edson Lobão e 14,55\% em Ribamar Fiquene e Scutellospora sp. com 29,84\% no munícipio de Ribamar Fiquene. Enquanto que o IF de espécies raras foi observado 4 gêneros, Claroideoglomus sp., 
em Governador Edson Lobão (0,53\%), Gigaspora sp., Governador Edson Lobão (0,21\%), Glomesporos sp., na á (1,32\%) e Paraglomus sp., Ribamar Fiquene (tabela 1).

\begin{tabular}{ccc}
\multicolumn{3}{c}{ Tabela 1- Frequência de Isolamento, Fonte: Própria } \\
\hline GÊNEROS & Governador Edson Lobão & Ribamar Fiquene \\
Acaulospora sp1. & $29,41 \%$ & $14,55 \%$ \\
Claroideoglomus sp1. & $0,53 \%$ & $0 \%$ \\
Gigaspora sp1. & $0,21 \%$ & $0 \%$ \\
Glomus sp1. & $62,50 \%$ & $53,08 \% \%$ \\
Glomesporos sp1. & $0 \%$ & $1,32 \% \%$ \\
Paraglomus sp1. & $0 \%$ & $1,21 \%$ \\
Scutellopora sp1. & $7,23 \%$ & $29,84 \%$ \\
\hline * IF: espécie dominante (IF > 75\%), espécie mais comum $(50>$ IF < $75 \%)$, espécie comum $(25$ \\
$>$ IF < 50\%), e espécies
\end{tabular}

\section{Conclusões}

Com os resultados encontrados podemos concluir que em solo de Cerrado sob pastagem os FMA são os de maior adaptabilidade, semelhante aos encontrados em outras áreas de Cerrado, porém apresentou a presença de outros gêneros, o que reforça a necessidade de mais estudos para assim contribuir no entendimento sobre a diversidade FMA no bioma do Cerrado e como a substituição de área nativa por pasto afeta essas comunidades do solo.

\section{Referências}

BERBARA, R. L. L.; SOUZA, F.A.; FONSECA, Henrique M. A. C. Fungos micorrízicosarbusculares: muito além da nutrição. In: FERNANDES, M. S (Ed.). Nutrição Mineral de Plantas. Viçosa, MG: Sociedade Brasileira de Ciência do Solo, 2006. p. 53-88.

FERNANDES, S.G. Fertilidade do solo e atividade micorrízica em áreas de agricultores familiares no norte de Minas Gerais. Montes Claros- MG, 2011.

FERREIRA, D.A.; CARNEIRO, M;A;C.; SAGGIN, O.J.J. Fungos micorrízicos em latossolo vermelho do Cerrado sob diferentes usos. Revista Brasileira de ciências do solo, v.36, p.51$62,2012$.

GERDEMANN, J.W.; NICOLSON, T.H. Spores of mycorrhizalEndogone species extracted from soil by wet sieving and decanting.Transactions of British Mycological Society, Cambridge, U.K., v. 46, n.2, p.235-244, 1963.

INVAM - INTERNATIONAL CULTURE COLLETION OF VESICULAR ARBUSCULAR MYCORRHIZAL FUNGI, 2001. Disponível: < http://invam.caf.wvu.edu/>. 
JENKINS, W. R. A rapid centrifugal-flotation technique for separating nematodes from soil. Plant Disease Reporter, v. 48, n. 9, p. 692, 1964.

MIRANDA, J.C.C. Cerrado: micorrizaarbuscular: ocorrência e manejo. Planaltina, DF: Embrapa Cerrados, 2008.169p.

MOREIRA, F.M. S; SIQUEIRA, J.O. Microbiologia e Bioquímica do solo. 2 ed. atual. eampl. Lavras: Editora UFLA, 2006.729 p.

SCHENCK,N.C.; PÉREZ, Y. Manual for the identification of VA-mycorrhizal fungi. 3.ed. Gainesville: Synergistics - Publications, 250 p.1990.

SILVA, S.L.O. Ocorrência de fungos mícorrizicos arbusculares em diferentes sistemas de terra. 2010. Dissertação (Mestrado). Universidade Estadual do Maranhão. São Luís-Ma. p.44, 2010 .

SILVA JUNIOR, J.P. CARDOSO, E.J.B.N. Micorrizaarbuscular em cupuaçu e pupunha cultivados em sistema agroflorestal e em monocultivo na Amazônia Central. Pesq.Agropec. Bras., v. 41, p.819-825, 2006.

SOUZA, D.M.G. LOBATO, E.Cerrado: Correção do solo e adubaçãp. 2 ed. Brasília, Embrapa Informação e Tecnologia, 2004.416p.

ZHANG ,Y.; GUI, L. D.; LIU, R. J. Survey of arbuscularmycorrhizal fungi in deforested and natural forest land in the subtropical region of Dujiangyan, southwest China. Plan Soil. v. 261, p. 257-263. 2004. 